\title{
Biofueling Rural Development: Making the Case for Linking Biofuel Production to Rural Revitalization
}

\section{Introduction}

Biofuels have emerged as one of the most promising new sectors for rural America. Primarily a Midwestern phenomenon until now, the expected shift to biomass-as opposed to the current grain and oilseed feedstocks-for producing biofuels will expand the biofuel sector's impact and influence nationwide. Politicians and proponents tout the potential for biofuels to stimulate rural job creation and economic growth and increase energy independence as key reasons for providing public support for the industry. But in the rush to grow the sector, the benefits to rural communities may be muted or lost if federal, state and local policies and programs that help determine the sector's ownership, scale and structure do not sufficiently support rural development priorities.

\section{The Promise and Limits of Biofuels}

Biofuels are currently produced almost entirely from grains and oilseeds, which has generally meant corn and soybeans in the United States. Construction of and investment in ethanol refineries and biodiesel plants have skyrocketed in the last few years, resulting in over 4.8 billion gallons of U.S. production in 2006, with another 3-6 billion gallons of new and planned construction and expansion. ${ }^{1}$ Concern is mounting about the impact of biofuel production on the environment and existing agriculture markets that supply the industry. The limitations of current feedstocks to meet our fuel needs are clear: even if we turned the entire harvested U.S. corn crop of 2005 into ethanol, it would equal less than 15 percent of the United States' current annual vehicle fuel use. ${ }^{2}$
Biofuels made from biomass (see box) offer the possibility of much higher production levels with potentially better environmental and economic benefits nationwide. While technologies to convert these materials into liquid fuels have been around for many years, until recently they have been considered too inefficient or costly to be commercially viable. Improved efficiency and lower costs of biomass conversion technologies, combined with the rising price of fossil fuels and increased government assistance, have almost eliminated this imbalance. The result can only be compared to a liquid gold rush, with companies ranging from small farmer-owned cooperatives and start-ups to corporate behemoths such as Goldman Sachs, Shell, Archer Daniel Midland and Cargill racing to develop biomass-based biofuel refineries.

As opposed to corn and soybeans, which are grown primarily in the Midwest, the United States has a nationwide biomass production capability. ${ }^{3}$ The amount of grasses, trees and crop and forest residues that could be produced and harvested in the U.S., if turned into biofuels, would meet much of the domestic fuel demand and, by some estimates, could even eliminate
Biofuels are gas or liquid fuels derived from biomass.

Biomass is a very broad term used to describe any plant or animal material, including crops, trees, other plants, and algae, but also manure, sludge, municipal waste and anything else organic in nature.

Cellulose is the carbohydrate that makes up a large portion of plant material (along with hemicellulose and lignin).

Feedstocks are raw material supplied to a machine or processing plant from which other products can be made. 


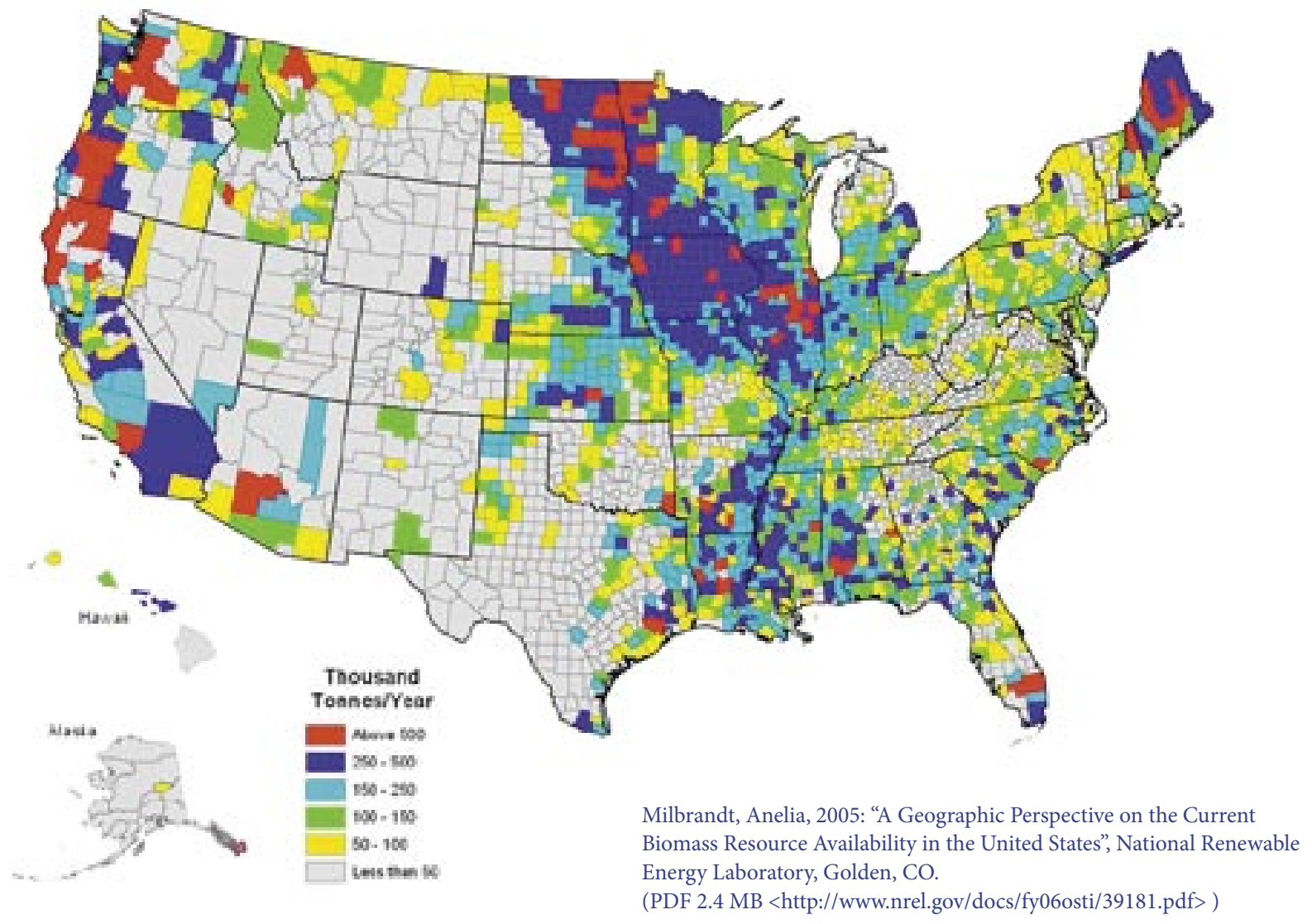

the need for fossil fuels entirely. ${ }^{4}$ Much is still needed for the biomass sector to truly emerge in terms of research, infrastructure development and supportive policies (from breeding work and appropriate equipment to contracting systems, fuel supply assessments, and facility siting and investment) but with increased focus and investment, these challenges are expected to be overcome in the coming years.

A shift to biomass could provide significant environmental benefits if it is produced in an ecologically and economically sustainable manner. For perennial and deep-rooted energy crops such as prairie grasses and fast-growing trees it is possible, with well-managed, certified production methods, to have less run-off, use fewer fertilizers and pesticides, increase water infiltration and retention, bring higher levels of biodiversity and wildlife habitat, and enhance carbon sequestration. The ability to use diverse feedstocks, including materials currently considered as waste, can also reduce pressure on current land use, while providing a market for materials that currently have little or no value.

Unlike corn or soybeans, which are harvested, transported and stored relatively easily and efficiently, biomass is generally bulky, less dense and much more difficult to move around and store for long periods. This speaks to a new adage, "all biomass is local," as, by its nature, biomass is more suited for processing close to the feedstock production. Creating small refineries may prove challenging as they require high levels of capital investment to be competitive in a global market. But for long-struggling rural communities, this may offer the promise of new investment, job growth and revitalization.

These positive and needed outcomes, however, are not assured in the creation of a biomass economy. Depending on which feedstocks, production systems and ownership approaches are proposed and ultimately adopted, these multiple benefits may or may not result. Production systems that are large in scale and owned primarily by outside investors would limit the rural development potential. And if the focus is only on production and yield, the environmental benefits could actually become threats, as excessive biomass collection could increase erosion, reduce diversity and wildlife habitat, denigrate soil quality and even increase monocultural production-all to the ultimate detriment of the rural resource base and economy.

Sustainable agriculture and environmental protection advocates rightly argue that biomass destined for biofuel needs to be produced and harvested in environmentally appropriate ways and are working to assure those methods 
through promotion of environmental standards and other regulations. For example, in the case of woody biomass from trees, developing wood supply assessment tools and certification systems capable of ensuring sustainable forest management are essential elements of an effective renewable energy policy. The same focus is needed for the community economic development components. For farmers, landowners and rural communities to truly benefit, policies and incentives need to be established that equally support rural development goals and environmental and economic considerations.

\section{Biomass "Fueling” Rural Development}

To date, most recommendations for creating a successful bio-economy have noted the potential for rural development, but have failed to address how communities might participate in this process. A significant exception to this rule is David Morris of the Institute for Local Self-Reliance and what he calls the "Carbohydrate Economy." Writing and advising on the topic for several decades, he presents the most compelling and detailed approach for rural community development through the emerging bio-based sector.

Ownership of the refineries by local farmers and community members is seen as the key aspect to sustainable rural development. Local ownership assures that the facility is based to some extent on local resources and needs, and that much of the money generated remains in the local economy. Recent studies have shown that while there is some economy of scale in larger systems, this tops out at a relatively modest level-around 40 million gallons a year for corn ethanol, a base level of production for the current industry. On the other hand, recent studies have shown that the benefits of smaller, locally owned refineries for communities is much higher, including a one-time boost of about $\$ 142$ million to the local economy; creation of about 40 full-time jobs; and an increase in annual direct spending in the community of around $\$ 56$ million. And spending of dividends by community investors has been found to contribute significantly more to the local economy-an average of an additional 821 jobs, an increase of $\$ 37$ million in household income, and over $\$ 60$ million more in Gross State Product-than what a community gains through local siting of an absentee-owned plant. ${ }^{5}$

While communities can do much on their own to support such development, governments and policymakers have a crucial role to play. Federal and state governments already spend substantial funds on research, development and promotion of biofuels. Policies targeting local production of feedstocks and incentives for the development and introduction of appropriate scale biomass conversion technologies

\section{Technologies for Use of Biomass}

Biomass feedstocks from trees, crops, animal wastes or other sources can be used to provide energy in a number of different ways. These include making solid fuels, biogas, or a range of liquid fuels that can be used to meet needs for heating, power, and transportation. The various technologies employed to convert biomass to energy have very different efficiencies, economic implications, and appropriate applications. When converting wood residues into cellulosic ethanol, for example, the energy content of the ethanol produced is about $50 \%$ of the available energy in the original feedstock. Converting wood residues into solid pelletized fuel captures all of the input energy in the wood feedstock but uses a significant amount of electricity in the process, giving a net $80 \%$ efficiency for the conversion.

Similarly, biomass can be used to produce different kinds of energy, including: industrial process heat; space heat for individual buildings or district heat for multiple buildings; combined heat and power (CHP); or electrical power produced at stand-alone power plants. These technologies have a range of net efficiencies from about 75\% for industrial process heat down to about $20 \%$ for a conventional 20 MW wood-fired power plant.

Consequently, while conversion of biomass to liquid fuels is one promising option, it is important to consider the potential of liquid fuels in the context of other technologies for using biomass to maximum advantage in terms of energy efficiency and local economic return.

ECONOMIC IMPACTS OF COMMUNITY-OWNED vS. Absentee-owned Facilities

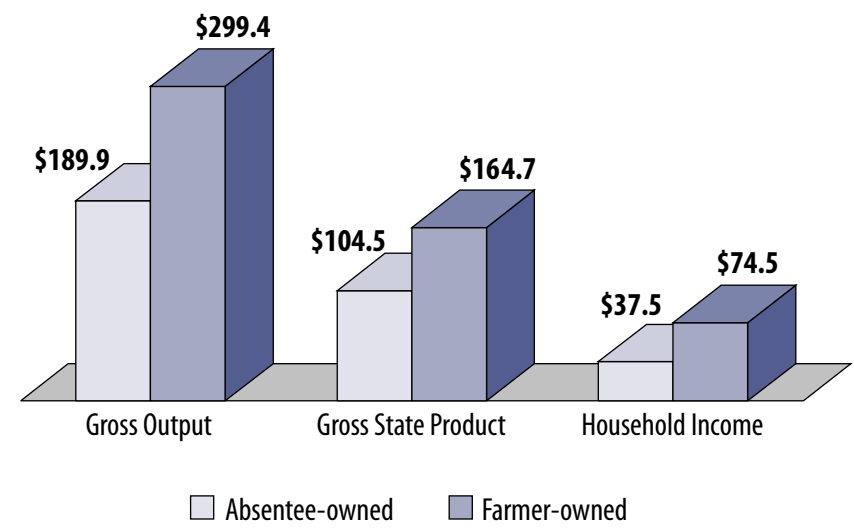

Urbanchuk, John. "Economic Impacts on the Farm Community of Cooperative Ownership of Ethanol Production," for the National Corn Growers Association September 2006 (http://www.ncga.com/ethanol/pdfs/2006/ FarmerOwnedEthanolEconomicImpact.pdf) 
and production systems can assure that there are opportunities in the biofuels sector for farmer- and community-owned facilities.

For the nascent biofuels sector, which is competing with an established and well-subsidized fossil fuel industry, incentives and preferences can be an essential tool to help level the playing field. The Federal Biobased Products Purchasing Program created in the 2002 Farm Bill, which requires federal agencies to purchase biobased products when available, appropriate and affordable, is an example of how preferences can be used to support market development. Similar preferences could be established for biofuels produced by community-owned facilities.

Despite language supporting rural-based production, current federal incentives for the biomass fuels industry may actually inhibit community participation by promoting production systems without consideration of local impacts and benefits. For instance, biofuel conversion processes that are designed to use only one type of material would limit the range of feedstocks and promote monocultural crop production, to the detriment of the environment and the potential range of local suppliers. And without specific requirements for locally owned production and the influx of corporate investment into the sector, the likelihood is that the pilot biomass facilities called for in recent legislation will be primarily corporate owned, leaving farmers and communities out of the initial, and potentially crucial, first round of development.

Examples exist for how to direct the incentives in a way that promote community-based development. Minnesota state policies created in the 1990s gave farmers assistance in starting up refineries through a loan program and provided incentives to in-state ethanol production for the first 15 million gallons of ethanol produced each year. This approach helped grow the biofuels sector so that today, more than three-quarters of current ethanol production facilities in the state are majority farmer-owned. With over 30 percent of corn growers in Minnesota now investors in ethanol cooperatives, the industry is providing a significant value-adding opportunity not only for local farmers, but also to Minnesota's rural communities. ${ }^{6}$

\section{Policies for Biofuels and Rural Development}

Two specific pieces of federal legislation-the Farm Bill and the Energy Bill-have the most influence over how the biofuel sector develops. With the expected rewriting of the Farm Bill in 2007, and the ongoing implementation of the Energy Act provisions, some key programs and funding mechanisms could be used to emphasize and support rural development in biofuel sector assistance. In particular, the Farm Bill's Rural Development Title could provide substantially more funding to assist rural business start-ups and provide farmers and rural communities access to capital. The Farm Bill's Energy Title and the Energy Policy Act, could put greater emphasis on farmer and community scale development, particularly in the Bioenergy Program, which allows for cooperation with industrial and academic partners; the Biorefinery Program; and the Biomass Research and Development Program. As detailed in a September 2006 David Morris paper, incentives for biomass fuel production could be crafted to make them more accessible and appropriate for community-based development. ${ }^{7}$

Biofuels policy does not need to be exclusively federal territory, however. As illustrated by Minnesota's experience, states, too, can play a role in promoting rural development while growing the biofuels industry, through programs that target community-based development, provide tax incentives and establish dedicated markets. County, township and village governments, which are closest to the biofuel economy, in some ways may play the most critical role in promoting biofuel-based rural development. Through their roles in determining zoning, local tax packages, infrastructure development and uses of community-property, commissioners, town planners and other local elected officials can assure that community needs and assets are considered when determining which developments receive local governmental support. 


\section{Recommendations}

- Prioritize Rural Development Considerations in Biofuel Incentives: State-provided support has helped farmer-owned ethanol processing facilities become established and profitable, while returning more in added tax revenues than the support programs cost. Federal policy can expand on these existing state-based efforts to prioritize community ownership opportunities alongside production and environmental considerations in implementing biofuel policies.

- Help with Start-up Capital: While many farmers and rural communities would like to develop biofuel facilities, they often do not have access to the kind of capital required, especially for biomass refineries, which are expected to cost significantly more than current corn-based facilities. Creation of a revolving loan fund or tax credit for first-time community biofuel investors would allow more rural residents to participate in the new sector's development. Work also needs to be done with rural banks and lenders to assure that funding for community-based projects is available at competitive rates.

- Education and Technical Assistance: As with capital, many rural communities do not have the resources or knowledge necessary to establish and operate a biorefinery facility. Public assistance at all levels in the form of outreach and technical support to farmers and community-owned facilities could assure that rural citizens have access to the information and training needed to inform investment.

- Make Public Research Public: If conversion and other technologies are created with federal or land grant university support, then the public should be able to help determine what type of licenses and patents are allowed. Creation of special incentives for community-owned refineries around government-supported licensing technologies and patents would be a valuable way to assist community-supported projects in becoming competitive.

- Make Biofuels a part of Conservation Programs: Bolster the current Conservation Security Program (CSP), which provides support for sustainable agricultural practices, by supporting cultivation of biofuels crops using sustainable practices and by creating preferences for biofuels use in enrollment criteria under CSP. Land coming out of Conservation Reserve Program (CRP) contracts could be provided shorter-term and reduced value contracts under CSP or a new program that allow for biomass production based on strong environmental criteria to ensure soil protection and wildlife habitat goals.
- Ensure that Biomass Feedstocks are Sustainable Over the Long Term: Biofuels can be a viable alternative to non-renewable energy sources only if certain measures are taken to ensure long-term ecological sustainability. The federal government or states should require independent certification or other measures to ensure that all forests and agricultural lands managed for biomass production meet standards that sustain long-term ecological health. Also, wood supply assessments should be conducted that take into account all aspects of long-term ecological and economic sustainability.

At this critical juncture, when the sector's conversion technologies, infrastructure and ownership are being established, policies can be developed-or, in many cases, strengthened and funded - to assure that rural communities continue to participate in and benefit from the biofuel industry. Wall Street investors will undoubtedly increase the amount of fuel produced, but unless policymakers emphasize rural development aspects in the creation of incentives and programs to expand the industry, farmers and rural citizens may be left behind and returned to their role of low-cost feedstock suppliers. With such an opportunity to revitalize our countryside, it is up to policymakers to make sure that ethanol and biodiesel fuel not only our vehicles, but also sustainable rural development across the United States.

\section{For Further Reading:}

Institute for Agriculture and Trade Policy: Cultivating a New Rural Economy and other related writings focus on the bioeconomy and rural communities http://www.iatp.org

Institute for Local Self Reliance: New Rules Project and Carbohydrate Economy are two ILSR program areas that focus on renewable energy and community ownership http://www.ilsr.org

The Environmental and Energy Study Institute (EESI): A non-partisan group that does analysis of Farm Bill and Energy Policy Act from a rural community and environmental perspective

http://www.eesi.org/programs/agriculture/agriculture.htm

Natural Resources Defense Council: Growing Energy: How Biofuels Can End America's Oil Dependence (2004). Study highlighting the ability of biofuels to meet U.S. transportation fuel needs http://www.nrdc.org/air/energy/biofuels/contents.asp 
Apollo Alliance: New Energy for America: The Apollo Jobs Report: For Good Jobs \& Energy Independence (2004). Identifies how a new energy policy can provide jobs and rural development opportunities while improving environmental quality

http://www.apolloalliance.org/jobs/index.cfm

Worldwatch Institute: Biofuels for Transportation: Global Potential and Implications for Sustainable Agriculture and Energy in the 21st Century (2006) http://www.worldwatch.org/taxonomy/term/445

\section{U.S. Department of Agriculture/Department of Energy:} Biomass as Feedstock for a Bioenergy and Bio-products Industry: The Technical Feasibility of a Billion-Ton Annual Supply (2005)

http://feedstockreview.ornl.gov/pdf/billion_ton_vision.pdf

$25 x^{\prime} 25$ is a renewable energy initiative backed by organizations and individuals united by a common interest in making America's energy future more secure, affordable and environmentally sustainable. A recent study conducted by researchers at the University of Tennessee Agricultural Economics Department concludes that America's farmland and forests can provide $25 \%$ of US energy needs while continuing to produce safe, abundant and affordable food, feed and fiber. The study also looks at the impacts of this production on the agricultural sector and the overall US economy. http://www.agpolicy.org/ppap/REPORT\%2025x25.pdf

\section{Endnotes}

\footnotetext{
${ }^{1}$ With the boom in interest and investment in ethanol and biodiesel facilities, projections for ethanol expansion change daily. This range includes projects that have begun construction, filed for permits and undertaken financing and is based on information gathered by IATP from the Renewable Fuels Association, BBI International and other sources.

${ }^{2}$ USDA NASS 2005 Crop report; U.S. Department of Energy U.S. Fuel Consumption data.

${ }^{3}$ USDA/DOE (2005) Biomass as Feedstock for a Bioenergy and Bio-products Industry: The Technical Feasibility of a Billion-Ton Annual Supply.

${ }^{4}$ NRDC (2004) “Growing Energy" report.

${ }^{5}$ John Urbanchuk has conducted several studies $(2002,2004,2006)$ assessing the economic impacts on the farm community of cooperative ownership of ethanol plants, all of which point to a higher return to communities than absentee-owned facilities. The most recent study concludes that a community-owned facility will increase the local economy (measured by Gross State Product) half again as much (56 percent) as an absentee-owned plant, "Economic Impacts on the Farm Community of Cooperative Ownership. See www.ncga.com for these studies.

${ }^{6}$ IATP research based on conversations with Minnesota Corn Growers and D. Morris, "Putting the Pieces Together: Commercializing Cellulosic Ethanol," Institute for Local Self Reliance, http://www.newrules.org/agri/ celluloseethanol.pdf

${ }^{7}$ Ibid.
}

\section{A U T H O R}

Jim Kleinschmit is the Director of the Rural Communities Program at the Institute for Agriculture and Trade Policy in Minneapolis, Minnesota

The Institute for Agriculture and Trade Policy (IATP) promotes resilient family farms, rural communities and ecosystems around the world through research and education, science and technology, and advocacy.

\section{A C K N O W L E D G E M E N T S}

The author would like to thank IATP's Ben Lilliston for his help in preparing the brief, Dick Levins, Andrea Colnes, David Freshwater and the Hatcher Group for their review of the manuscript and Priscilla Salant and Amy Seif of the Carsey Institute for their assistance throughout the process.

\section{$\triangle$ UNIVERSITY of NEW HAMPSHIRE}

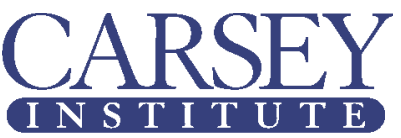

Building knowledge for families and communities in the 21st Century.

The Carsey Institute at the University of New Hampshire conducts independent, interdisciplinary research and communicates its findings to policymakers, practitioners and the general public.

Huddleston Hall

73 Main Street

Durham, NH 03824

(603) 862-2821

www.carseyinstitute.unh.edu

The Carsey Institute Reports on Rural America are supported by the Annie E. Casey Foundation's initiative to strengthen rural families, the Ford Foundation, and by the W.K. Kellogg Foundation. 